Uludag Univ. J. Fac. Vet. Med.

33 (2014), 1,2: 79-81

\title{
Bir Köpekte Aşırı Doz Neostigmin Uygulanması Sonucu Şekillenen Tetraparezi Olgusu ve Sağaltım Sonuçları
}

\author{
Serkan ÇATIK ${ }^{1} \quad$ Evren BULGAÇ ERTEN ${ }^{2} \quad$ Hakan SALCI ${ }^{2}$
}

Geliş Tarihi: 07.05.2014

Kabul Tarihi: 29.09.2014

\begin{abstract}
Özet: Sekiz aylık, Rotweiller ırkı, erkek bir köpek, ani şekillenen felç nedeniyle kliniklerimize sevk edildi. Köpeğin son günlerde konstipasyon şikayeti çekmesi nedeniyle barsak peristaltiğini arttırmak için $\mathrm{B}_{1}-\mathrm{B}_{6}$ vitamini, neostigmin ve parafin likit uygulandığını belirtildi. Bu uygulama sonrası ekstremitelerinde güçsüzlük, inkoordinasyon, tetraparezi, solunum güçlüğü, kusma ve yumuşak kıvamlı defekasyon görüldüğü ve tedavi olarak deksametazon ve sıvı sağaltımı uygulandığı bildirildi. Klinik ve nörolojik muayeneler sonucu hastada tetraparezi tanımlandı ve atropin sülfat uygulamasına cevap alınamadı. $\mathrm{B}_{1}-\mathrm{B}_{6}$ vitamini, E vitamini - selenyum ve sıv1 uygulaması ile birlikte diklofenak sodyum, ranitidin ve ampisilin-sulbaktam tedavi protokolü olarak seçildi. Diklofenak sodyum uygulamasının 2. gününden itibaren kademeli olarak hastada düzelme ve 10 günde tamamen klinik geri dönüş gözlendi.
\end{abstract}

Anahtar Kelimeler: Neostigmin, tetraparezi, diklofenak sodyum, köpek.

\section{The case of Tetraparesia Resulted from Hyperdose Neostigmine Application and Its Treatment Results}

\begin{abstract}
Eight-month-old, Rottweiler breed, a male dog was referred to our clinics with the cause of sudden onset paralysis. Due to recently encountered constipation problem, it was informed that $\mathrm{B}_{1}-\mathrm{B}_{6}$ vitamin, neostigmine and paraffin liquid had been applied to increase the intestinal motility. Following the application, it was emphasized that limb weakness, in coordination, tetraparesis, dispnea, vomiting and soft defecation had seen, and dexamethasone and fluid therapy had been applied. After clinic and neurologic examinations, tetraparesis was diagnosed but application of atropine sulfate was not effective. Together with the $\mathrm{B}_{1}-\mathrm{B}_{6}$ vitamin, vitamin $\mathrm{E}-$ selenium and treatment protocol of diclofenac sodium, ranitidine and ampicillin-sulbactam was used. Gradually, patient started the clinical healing at 2nd day after medical management and the complete clinical return was achieved at $10^{\text {th }}$ day.
\end{abstract}

Key Words: Neostigmine, tetraparesis, diclofenac sodium, dog.

\section{Giriş}

Neostigmin bir quaterner amonyum bileşiği olup orta süre etkili antikolinesterazlar grubunda yer alır. Enjeksiyonu sonrası yaklaşı 1 dakika içinde etkisini göstermeye başlar ve plazmada 10 dakika içinde pik seviyeye ulaşır.
Etkisi 20-30 dakika kadar devam eder ve yar1lanma ömrü yaklaşık 77 dakikadır ${ }^{4}$.

Asetilkolinesterazlar asetilkolinin sinapslardaki direncini ve presinaptik reseptörler üzerine etkileri nedeniyle de asetilkolin salınımını artırırlar. Neostigmin ve diğer quaterner amonyum bileşiği antikolinesterazların iskelet kasları

1 Uludağ Üniversitesi Veteriner Fakültesi, İç Hastalıkları Anabilim Dalı, Bursa.

2 Uludağ Üniversitesi Veteriner Fakültesi, Cerrahi Anabilim Dalı, Bursa. hsalci@uludag.edu.tr 
üzerine direkt etkisi vardır. Aşırı dozlarda kullanımı nöromusküler kavşakta asetilkolin birikimine ve depolarizasyon blokajına yol açar. Hatta öncesinde bir kas gevşetici vermeksizin ya da hızlı bir şekilde uygulanması kas paralizlerine neden olabilir ${ }^{3,4}$.

Sinapslardaki yoğun asetilkolin, nöromusküler kavşaktaki reseptörlerin tekrarlayan stimülasyonuna ve asetilkolinin etki süresinin artmasına neden olur. Nöromusküler kavşakta depolarizasyon ile aksiyon potansiyeli gelişimi arasındaki senkronizasyonu bozularak asenkronize eksitasyon, kasların fibrilasyon ve fasikülasyonuna oluşur. Ayrıca neostigminin yüksek dozda uygulanması sonucu bradikardi, hipotansiyon, bronkospazm, hipoksi, sekresyon artışı, myosis, gastrointestinal motilite artışı nedeniyle kusma ve ishale şekillenir ${ }^{2-4}$.

Neostigmin özellikle anestezi sonrasında rezidüel nöromusküler bloğu antagonize etmek ve gastrointestinal motiliteyi artırmak için kullanılır ${ }^{2} \mathrm{Bu}$ olgu sunumu Rottweiller irk1 bir köpekte karşılaştığımız aşırı doz neostigmin uygulaması sonucu şekillenmiş tetraparezi tablosunu ve uygulanan sağaltım protokolünün rapor edilmesini amaçlamıştır.

\section{Vaka Geçmişi}

Rotweiller 1rkı, 8 aylık, erkek, 26 kg ağırlığında bir köpek 2 gün önce ani şekillenen felç ve ayağa kalkamama şikayetiyle bir veteriner hekim tarafindan kliniklerimize sevk edildi. Veteriner hekim ve hasta sahibi ile yapılan konuşma neticesinde, hastanın ev yemekleri ve kuru mama ile beslendiği, son günlerde konstipasyon problemi yaşaması nedeniyle özel bir veteriner kliniğine götürülerek burada barsak peristaltiğini arttırmak amacıyla sc. yoldan $2 \mathrm{ml}$ $\mathrm{B}_{1}-\mathrm{B}_{6}$ vitamini, $2 \mathrm{ml}$ neostigmin ve yaklaşı 20 cc kadar da parafin likit'in peros uygulandığ bildirildi. $\mathrm{Bu}$ uygulamalardan yaklaşık yarım saat sonra hayvanın ekstremitelerinde güçsüzlük, inkoordinasyon ve tetraparezi ile birlikte solunum güçlüğü, kusma ve yumuşak kıvamlı dışk1 yaptığı bildirildi. Aynı klinikte ilaçlara karş1 bir hipersensitivite gelişmiş olabileceği düşüncesiyle de tek doz $3 \mathrm{ml}$ deksametazon im. olarak uygulandığ 1 ve 2 gün boyunca da $\% 5$ dekstroz + laktatlı ringer solusyonunun infüze edildiği bildirildi. Ancak hastadaki klinik tablonun değişmediği bildirildi.

Hastanın genel muayene bulgularında pulzasyon:112/dk, respirasyon 56/dk, beden 1sis1 $38,6^{\circ} \mathrm{C}$, kapillar dolum zaman1 2 sn ve lenf yumrularının ise normal olduğu saptandi. Hasta ayağa kalkamıyordu ve tüm ekstremitelerde ve boyunda relaksasyon mevcuttu. Nörolojik olarak yapılan pikürlere ve reflekslere herhangi bir tepki alınamadı. Anal refleks, dışkılama ve idrar yapma istemliydi. Ortopedik muayenede kemik dokuya spesifik herhangi bir patolojiyle de karşılaşılmadı. M. masseter gibi çiğneme kaslarını da hareket ettiremediğinden kuru mamayı çiğneyemiyor fakat su ve sıvı gidaları alıp tüketebiliyordu. Rutin hemotolojik muayenede parametrelerin referans aralığında olduğu saptandı.

Hasta getirildiğinde tek doz $0,2 \mathrm{mg} / \mathrm{kg}$ atropin sülfat (Atropin® \% 2, Vetaş, İstanbul) iv., $2 \times 1$ litre $\% 5$ dekstroz+laktatl 1 ringer ve farkl dengeli elektrolit solusyon infüzyonları, 1x1 $2 \mathrm{ml} \mathrm{B}_{1}-\mathrm{B}_{6}$ vitamin kompleksi sc. ve 3 günde bir E vitamini - selenyum (E-Sevil ${ }^{\circledR}$, Vilsan, Ankara) $1 \mathrm{ml} \mathrm{im}$. olarak 1 hafta boyunca uygulandi. Ayrica hastaya sivi gidalar oral yoldan verildi. Bu tedavi protokolüne diklofenak sodyum (Voltaren ampul ${ }^{\circledR} 75 \mathrm{mg} / 3 \mathrm{ml}$, Novartis, İstanbul) $2 \times 1 \mathrm{mg} / \mathrm{kg}$ im., ranitidin (Ulcuran ampul ${ }^{\circledR}$, Mefar, İstanbul) $3 \times 3 \mathrm{mg} / \mathrm{kg}$ sc. ve ampisilin - sulbactam (Sulbaksit flakon ${ }^{\circledR}$ 1gr, TümEkip, İstanbul) $2 \times 20 \mathrm{mg} / \mathrm{kg} \mathrm{im}$. uygulaması dahil edildi. Diklofenak sodyum uygulamasının 2. gününden itibaren hastanın boyun kaslarını oynatabildiği ve kuru mamayı rahatlıkla yiyebildiği görüldü. 4 günlük uygulamadan sonra hasta ön ekstremitelerini etkili bir şekilde kullanabildi ve sterno-abdominal pozisyonda kendi isteğiyle gelerek ayağa kalkmak için çabalamaya başladı. Arka ekstremitelerde zayıf da olsa hareketler başladı. Uygulamanın 7. gününde hasta desteklenerek ayakta durabildi ve birkaç kısa adım atabildi. 10. güne kadar diklofenak sodyum uygulandı ve hayvanın normal yürümeye başladığı görüldükten sonra da uygulamaya son verildi. Tedaviyi takiben 3 . haftaya kadar ekstremitelere pasif hareketler yaptırarak fizik tedavi de uygulandi. Bu tedavi sonrasinda hasta yürür şekilde sahibine teslim edildi.

\section{Tartışma}

Glycopyrronium, neostigmin'in aşırı doz uygulamas1 sonras1 veya yan etkileri görüldüğünde uygulanan en iyi antagonist olduğu ve atropine göre daha hızlı etki gösterdiği bildirilmektedir ${ }^{4}$. Hastanın anamnez bilgileri ve klinik muayenesi doğrultusunda şekillenen tetraparezi tablosunun aşırı dozda neostigmin uygulanması sonucu oluştu, glycopyrronium temin etme im- 
kanı bulunamadığ1 ve neostigmin kullanımı üzerinden 2 gün geçmiş olması nedeniyle (yarılanma ömrü 77 dakika) ilacın etkinliğinin sona erdiğini düşündürse de rezidü kalabilme ihtimali düşünülerek hastaya tek doz atropin sülfat literatüre atfen uygulanmıştır ${ }^{4}$. Toksikasyon söz konusu olduğundan dolayı atropin sülfat'in dozu yüksek tutulmuştur. Ancak bu uygulama hastanın genel durumunda herhangi bir değişiklik meydana getirmemiştir.

Neostigmin'in bradikardi meydana getirdiği ve aşırı dozda kullanımının myokardiyal infarktüs ve kardiyak arreste yol açtığı konusunda raporların olduğu bildirilmektedir ${ }^{5}$. Hasta kliniğimize getirildiğinde neostigmin uygulamasının ardından 2 gün geçtiği için aşırı dozda uygulamaya bağlı meydana gelebilen kalple ilişkili bulgular, hipotansiyon, bronkospazm, hipoksi, sekresyon artışı, myosis, kusma ve ishal bulguları görülmemiștir. Sadece neostigmin uygulandığında hastanın kustuğu, solunum güçlüğü çektiği ve dışkısının yumuşak kıvamda olduğu bildirilmiştir.

Diklofenak sodyum non-steroid antienflamatuar, analjezik ve antipiretik bir ilaçtır. Tendinitis, romatoid artritis, osteoartritis ve ankilozlu spondilitis tedavilerinde beșeri hekimlikte de sıklıkla kullanılmaktadır ${ }^{1}$. Uygulanan destekleyici tedaviye yanıt alınamaması ve nöromusküler kavşakta uzun süren asetilkolin etkisi düşünülerek tedaviye antienflamatuar bir ilaç eklenmesi gerektiği düşünülmüştür. $\mathrm{Bu}$ amaçla güçlü antienflamatuar etkisi ve iskeletkas sistemindeki etkinliği nedeniyle diklofenak sodyum kullanımı tercih edilmiștir. Ancak en sık karşılaşılan yan etkilerinden olan gastrik irritasyon, gastritis, peptik ülser ve kanamalar bu ilacın kullanımını sınırlandırmaktadır ${ }^{1}$. Olası yan etkilerinden korunmak için hastaya günde üç kez $3 \mathrm{mg} / \mathrm{kg}$ canlı ağırlık dozunda ranitidin uygulanmış, tedavi sürecinde ve sonrasında mide ile ilgili herhangi bir probleme rastlanmamıştır.

Sonuç olarak, aşırı dozda neostigmin uygulaması sonrası tetraparezi şekillenmiş ve atropin sülfat ve destekleyici tedaviye rağmen iyileşme gözlenmemiş olan rotweiller 1 rkı bir köpekte, diklofenak sodyum uygulaması ile uygulanilan destek tedavisine alınan olumlu sonucun rapor edilerek küçük hayvan pratiği yapan meslektaşlarımızla paylaşılması yararlı olacaktır.

\section{Kaynaklar}

1. Aieloa, P.B., Borgesa, F.A., Romeiraa, K.M., Mirandab, M.C.R., Arrudac, L.B., Filhoc, P.N.L, Dragoc, B.C., Herculanoa, R.D., 2014. Evaluation of sodium diclofenac release using natural rubber latex as carrier. Materials Research, 17(2): in-press.

2. Cheng, C.R., Sessler, D.I., Apfel, C.C., 2005. Does neostigmine administration produce a clinically important increase in postoperative nausea and vomiting? Anesth Analg, 101(5), 1349-1355.

3. Mirakhur, R.K., Donati, F., 2003. Neuromuscular blocking agents and their antagonists. In: Healy TEJ, Knight PR, (Eds.), A Practice of Anesthesia. Arnold, London: 583-598.

4. Nair, V.P., Hunter, J.M., 2004. Anticholinesterases and anticholinergic drugs. Continuing Education in Anaesthesia, Critical Care \& Pain, 4, 164-168.

5. Sharma R., 2008. Muscle paralysis with an accidental overdosage of neostigmine. Acta Anaesthesiol Scand, 52(10), 1437. 
